\section{Kaltes Bein}

VON H. S. FÜEßL

Sie werden zu einem 78-jährigen multimorbiden Mann gerufen, der seit einigen Stunden plötzlich aufgetretene heftige Schmerzen im gesamten linken Bein hat. Die Ehefrau berichtet an der Haustür, dass der Mann herzkrank sei, Vorhofflimmern, hohen Blutdruck und Diabetes mellitus habe. Er habe tagsüber im Garten gearbeitet. Nachmittags empfand er am Kaffeetisch plötzlich einen peitschenartigen Schmerz im Bein. An Gehen - bisher problemlos möglich - war nicht mehr zu denken. Er legte sich ins Bett, auch weil er ein Kältegefühl im Bein hatte.

\section{Situation und Symptomatik}

Die Symptomatik ist sehr verdächtig auf einen akuten Gefäßverschluss, der durch eine arterielle Embolie hervorgerufen wurde. Ein Trauma liegt nicht vor. Für eine chronische PAVK ereignete sich das Geschehen zu plötzlich. Eine tiefe Beinvenenthrombose macht kaum so starke Schmerzen. Der Mann gibt keine Rückenschmerzen an, sodass ein radikulärer Schmerz unwahrscheinlich ist, obgleich die Gartenarbeit natürlich als Auslöser in Betracht käme.

Für eine akute arterielle Extremitätenembolie hat der Mann ein Risiko: das Vorhofflimmern. Sie erkundigen sich nach den Medikamenten und stellen fest, dass der Mann zwar eine Packung mit Marcumar ${ }^{\circledR}$ in der Hausapotheke hat, die Einnahme aber vor Monaten eingestellt hat. Ein alter Freund hatte unter Marcumar eine Hirnblutung bekommen.

\section{Sofortdiagnostik}

- Extremität betrachten: Leichenblässe des gesamten linken Beines;

- Hauttemperatur im Seitenvergleich mit dem Handrücken fühlen: Eiseskälte am linken Bein; je kälter das Bein, desto dringlicher die Situation

- Pulse tasten im Seitenvergleich, beginnend mit A. tibialis posterior und A. dorsalis pedis: links keine Fußpulse tastbar, A. poplitea links ebenfalls nicht tastbar, A. femoralis links dagegen gut gefüllt, hier kein Strömungsgeräusch. Pulsstatus rechtes Bein o. B.

- Motorik und Sensibilität orientierend prüfen: Parästhesien und Lähmungen mahnen zu höchster Eile!

- RR 150/110 mmHg, Herzfrequenz 110/min arrhythmisch.

Leider gibt es im Deutschen keine so einprägsame Regel wie im Englischen: die Fausregel mit den 6 x P.

$\begin{array}{ll}\text { _ Pain (Schmerz) } & \text { - Pulselessness (Pulslosigkeit) } \\ \text { _ Paleness (Blässe) } & \text { - Paralysis (Lähmung) } \\ \text { _ Paraesthesia (Parästhesien) } & \text { _ Prostration (Schock) }\end{array}$

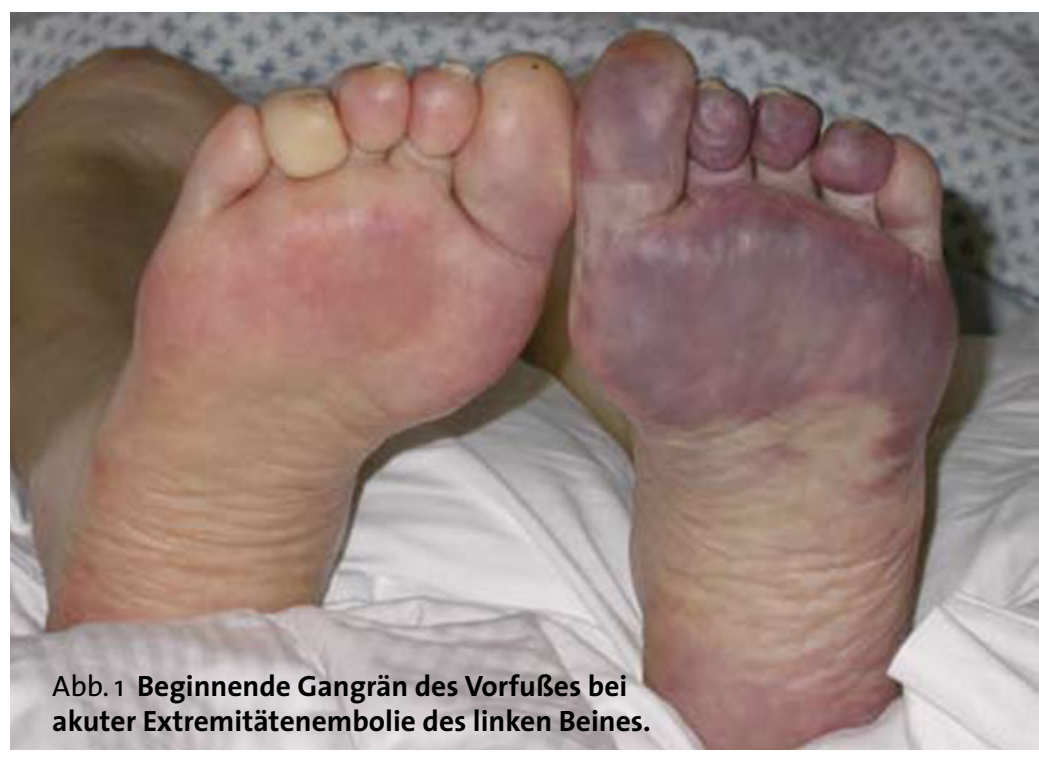

\section{Therapie}

Es ist Eile geboten!

- Lagerung: Tieflagern der betroffenen Extremität; Polstern mit Watte oder weichen Tüchern; Schutz vor Wärmeverlust und Drucknekrosen

- Venöser Zugang:

- Heparin 5000-10 000 IE i.v.

- Volumengabe, z. B. HAES $6 \% 250 \mathrm{ml}$

- Schmerzbekämpfung Opioide, z. B. Pethidin 50 mg i.v.

- Sedierung mit Diazepam 5 mg langsam i.v.

- Sofort Klinik verständigen, stationäre Notfalleinweisung (möglichst Abteilung für Gefäßchirurgie); Liegendtransport; Klinik über Heparingabe informieren

- Cave:

- Keine i. m. Injektionen wegen einer möglicherweise anstehenden Lysebehandlung

- Keine vasodilatierenden Maßnahmen (Gefahr eines Steal-Effekts)

- Keine externe Wärmezufuhr (beschleunigt Gewebeuntergang).

\section{Woran noch denken, was noch tun?}

Unbedingt selbst die Klinik anrufen und die Umstände und die Dringlichkeit persönlich dem Aufnahmearzt mitteilen. Die Extremität ist in akuter Gefahr.

Differenzialdiagnosen kommen kaum in Betracht, die Diagnose ist klinisch mit relativ großer Sicherheit zu stellen. Für das akute Vorgehen spielt es keine große Rolle, ob es sich um eine arterielle Embolie mit Emboliequelle oder lokal entstandene arterielle Thrombose bei einem Patienten mit Arteriosklerose handelt.

\footnotetext{
Anschrift des Verfassers:

Prof. Dr. med. H. S. FüeßI,

Leiter Somatischer Querschnittsbereich,

Isar-Amper-Klinikum, Klinikum München-Ost,

Ringstr. 33a, D-85540 Haar,

E-Mail: Fueessl@Krankenhaus-Haar.de
} 